\title{
Anal Adenocarcinoma
}

National Cancer Institute

\section{Source}

National Cancer Institute. Anal Adenocarcinoma. NCI Thesaurus. Code C5600.

An adenocarcinoma arising in the anal canal epithelium, including the mucosal surface,

the anal glands, and the lining of fistulous tracts. The prognosis is related to the stage at diagnosis. 